\title{
KANT ON Vital ForCES AND The ANALOGY WITH LiFE
}

\author{
Tyke Nunez
}

Forthcoming in the Proceedings of the 13th International Kant Congress 'The Court of Reason.' (Oslo, 6-9 August 2019) ed. by Camilla Serck-Hanssen and Beatrix Himmelmann. Berlin/Boston: Walter de Gruyter.

\begin{abstract}
:
In this essay I examine Kant's analogy with life from $\$ 65$ of the Critique of the power of Judgment. I argue that this analogy is central for understanding his notion of a natural end, for his account of the formative power of organisms in the third Critique, and for situating Kant's account of this power in relation to the Lebenskräfte of the vitalists.
\end{abstract}




\section{Kant on Vital Forces and The Analogy with Life ${ }^{1}$}

\section{$\$ 1-$ Introduction}

Kant holds matter, as matter, is inert; it is only moved by external forces or chemical powers (MFNS, 4:544). But organisms, paradoxically, are physical beings that seem to move themselves in a teleological way. To account for this apparent self-motion, and in developing his conception of organisms as natural ends, Kant relies on a number of analogies, including with artifacts, natural beauty, political states, and our own rational powers. Another such analogy is with life:

Perhaps one comes closer to this inscrutable property [i.e., the causality particular to natural ends] if one calls it an analogue of life: but then one must either endow matter as mere matter with a property (hylozoism) that contradicts its essence, or else associate with it an alien principle standing in communion with it (a soul), in which case, however, if such a product is to be a product of nature, organized matter as an instrument of that soul is \{either $\}^{2}$ already presupposed, and thus makes that product not the least more comprehensible, or else the soul is made into an artificer of this structure, and the product must be withdrawn from (corporeal) nature. Strictly speaking, the organization of nature is therefore not analogous with any causality that we know. (KU, 5:375-376)

While many interpreters quote the conclusion of this passage, not many attend to the analogy itself. Perhaps this is in part because the conclusion can sound dismissive. Or perhaps this is because it is uncommon for interpreters to attend to the distinction between the concepts of $<$ life $>$ and <organized matter $>$ (or <organism $>$ ) on which the analogy depends.

Nonetheless, not only is this passage the climax of Kant's discussion of the distinctive kind of material causality particular to natural ends, but it is also the key to situating Kant in relation to the debate over vital forces. Blumenbach's Bildungstrieb, Wolff's vis essentialis, or Herder's organische Kräfte, are all vital forces or life powers (Lebenskräfte). These forces are conceived on the model of Newtonian forces. They are supposed to be forces in nature that are at work in all living beings and that explain their peculiar self-motion. ${ }^{3}$ Here I set out to show that even if van den Berg might be right that Kant "does not explicitly point his 'regulative guns' at the concept of vital force" in his critical period $(2009,116)$, he does so implicitly in the analogy with life passage.

\footnotetext{
1 There is significant overlap between $\$ 2-4$ of this essay, and $\$ 3$ of my "Kant on Plants: Self-activity, Representations, and the Analogy with Life." That essay does not address vital forces.

2 The Cambridge ed. is missing the 'either': "jener Seele entweder schon voraussetzt" (my emph).

${ }^{3}$ I will dwell neither on the controversies between the $18^{\text {th }}$ century vitalists, nor on Kant's relation to them. The main fault line in the discussion of these issues is over how much of an influence Kant had on Blumenbach and his Göttingen school. Timothy Lenoir argued it was large, while Caneva, Zammito, and Richards argued that Lenoir overstates this influence.
} 
In it Kant is setting out to explain the material causality peculiar to natural ends or organisms. He does this by appealing to their formative power. This power is similar to the life-powers of these vitalists in that it too purports to explain the peculiar self-motion of organisms. We will see, however, that Kant holds life is the power of an immaterial being, a soul, to interact with a material being, an organism. And in rejecting the analogy with life, Kant is making clear that the formative power is not a life power, a Lebenskraft.

Still, the formative power is a teleological power. Teleological powers cannot be determinatively cognized as part of the mechanical natural world. At most they must be regulatively presupposed in the investigation of nature, and the formative power of an organism is like this. In this respect, we will see that the analogy with life does make the formative power more comprehensible. For, just as the soul directs the parts of the body so as to achieve its ends, the formative power directs the parts of an organism so as to maintain the whole.

It will turn out then that although the formative power is unlike the soul, in that it is not an immaterial principle of life, it is like the soul in that it is a teleological power. And even if Kant held that life powers are not admissible in natural teleology, the analogy with them is illuminating, up to a point.

\section{$\$ 2-$ Organisms as natural ends}

In $\$ 64$ and $\$ 65$ of the Critique of the Power of Judgment Kant presents his notion of a natural purpose or end (Naturaweck) and uses the example of a tree to exhibit three causal powers particular to natural ends: reproduction, growth, and self-maintenance or preservation. Something is a natural end or purpose, according to Kant, if "it is cause and effect of itself" (KU, 5.370). This definition includes two components, one of which natural ends share with artifacts, the other of which is distinctive. First, take a watch. "In a watch one part is the instrument [Werkzeng] for the motion of another" (5:374). There is a common form that unites all of the parts together into the whole, and this form ensures that each part is "present for the sake of the other." Second, unlike the watch, the tree has the power to circulate sap, take in oxygen, repair damage, create seeds, etc. In this respect, an organized being is more than a mere machine because it not only has "a motive power" (bewegende Kraft), but also "a formative power" (bildende Kraft) (KU, 5:375), where the latter power communicates a form to matter that does not have it, by organizing it. 
In section $\ 65$ Kant presents his concept of a natural end as a "determinate concept" in order to make precise this sense in which natural ends are related to themselves, reciprocally, as both cause and effects of themselves (KU, 5:370). In the case of the watch, the cause of the order and motion of the parts is external to it. It lies in the watch maker and her intention to build the watch according to her concept of it. This is the origin of the form of the watch. And in this respect the concept is the cause but not the effect of the watch. A natural end, however, is natural. We know of no natural cause that could imbue its parts with their form or their causality. Rather, as natural, its parts must themselves be cause and effect of their form, and of each other through that form. It is as if the watch and its parts were themselves the watch maker - as if they were the cause that brought the form into each other.

To describe the peculiarity of this kind of material causality, it will help to look at Kant's notion of an end (Zweck). As Newton notes (2017, 521), Kant defines an end both (1) as "the concept of an object insofar as it at the same time contains the ground of the reality of this object" (KU, 5:180, my emphasis) and (2) as the "object of a concept insofar as the latter is regarded as the cause of the former" (KU, 5:220, my emphasis). In the case of the watch, say, the end will be both the concept the watch maker has through which she produces the watch, as well as the watch itself that is produced. In the case of the tree, however, there is no known maker or intention. As Kant puts it, the "being that would possess the causality according to concepts appropriate for such a product" is unknown (KU, 5:373). For this reason, there is no end, as a concept, that we cognize as the intention through which the tree is produced.

Still, as many have noted, Kant holds that we judge that it is as though the organism was intentionally created in accord with a concept we posit, as if by some supernatural creator. This concept or universal is the species-form of the organism. And one mark of an objective end like a watch or a tree is the order (or "perfection," KU, 5:375; FI, 20:228) found in it. This order in the object is measured against "the concept of what sort of thing it is supposed to be" (KU, $5: 227 ;$ FI, 20:228). Insofar as the species-form is supposed to be more than a mere modelinsofar as it is also supposed to be, like the concept of the watch, the ideal cause of the organism-however, we know of no causal power that can bring this natural product about.

The reason is not merely that this product exhibits an order for which we cannot find a cause, but that it itself seems to be its own cause. The organism, as a natural end or purpose, is cause and effect of itself insofar as, like the watch, the parts are conceived of as existing for the sake of all of the other parts on account of the whole, through their form. In this respect, Kant compares the parts of the natural end to instruments (Werkezengen/organs) or gears (5:374), 
which the maker combines to make the product (e.g., the watch or end as object), in accordance with the idea of it (e.g., the watch plan or end as concept). But unlike the watch (and its gears), the parts of the natural end must also produce the other parts, in accord with their form as organs (e.g., roots, leaves, etc.), and produce the organism (e.g., tree) as the combination of these parts. In this respect, these organs are not merely brought together through the idea of an end in an external maker, but make themselves and their form, insofar as they both bring the form of the organism (end as concept) into matter that didn't have it to create organs and bring this form into the organism as a whole (end as object). ${ }^{4}$

Now, even considering only the natural formative power to grow, heal, and reproduce itself, Kant thinks we should be wary about claiming that organisms actually are natural ends. Being an end entails a creator with an intention, and with organisms we do not have insight into such a creating cause (e.g., KU, 5:400). In line with this, although Kant titles $₫ 65$, "things, as natural ends, are organized beings," he often seems to treat <organized being > or <organism> as empirical concepts, while he treats the concept <natural end $>$ as an a priori idea of reason (e.g., KU, 5:405; FI, 20:233). This a priori idea seems to then be specified in the empirical ideas of specific species-forms (e.g., KU, 5:373), and we judge that it is as if organisms fall under the concept <natural end $>$ or the more determinate concept of their species-form. Still, because we don't cognize the intentionally acting cause that created organisms, we are not permitted to make a judgment about how the thing in fact is-i.e., about the intention with which it was in fact made-but can only make a judgment that guides our investigations in to it, as if it were made in accordance with the species-form we posit.

\section{$\$ 3$ - Life and hylozoism}

The analogy with life passage, begins:

Perhaps one comes closer to this inscrutable property [i.e., the material causality particular to organisms] if one calls it an analogue of life: but then one must either endow matter as mere matter with a property (hylozoism) that contradicts its essence [...] (KU, 5:375-376)

What is hylozoism? And what is life, for Kant? Life, in the context of an embodied being, indicates the connection between a material and an immaterial substance (A393). This position from the first Critique is supported by the explanations consistently given across the metaphysics lectures. ${ }^{5}$ In these, Kant will distinguish life, as the interaction (commercio) of a

\footnotetext{
4 This sketch of Kant's account of the structure of the causal powers found in organisms combines elements from McLaughlin (2014) and Ginsborg (2015).

${ }^{5}$ See: Met-L1, 28:282-287; Met-K2, 28:753-755, 736, Met-D, 28:671; Met-M, 28:904-914; Met-V, $28: 441$.
} 
material body with a soul, from the principle of life, which is this immaterial soul. To take one characteristic example, in the 1782/83 Mrongovius transcripts he calls the connection of the soul and the body, their "interaction <commercium>" and says this "constitutes life" (Met-M, 29:904; 29:908). He then claims that, "thus the principle of life with human beings is not the body, but rather the soul" (29:914). ${ }^{6}$

He discusses hylozoism more fully in a passage from the Metaphysical Foundations of Natural Science. There he claims that "matter, as such, is lifeless" (4:544). The Second Law of Mechanics, the law of inertia, states, "every change in matter has an external cause" (4:543), and "the inertia of matter is, and means, nothing else than its lifelessness, as matter in itself" (4:544). Whereas,

Life is the faculty of a substance to determine itself to act from an internal principle, of a finite substance to change, and of a material substance [to determine itself] to motion or rest, as change of its state. ${ }^{7}$

Properly speaking, in this passage Kant presents three conceptions of life. The first, in terms of self-activity, will apply to finite and infinite beings. The second, as a self-active change, is restricted to finite beings. And the third, as self-active change in motion, is restricted to material finite things. The third will be our focus.

Because the explanation of life here is in terms of motion and rest it is proper to the science of extended nature-physical, movable objects—and it seems to allow that material beings can be alive. But as the rest of the Foundations passage attests, this is not straightforwardly so. In the next sentence Kant turns to the issue of what exactly this internal principle of self-activity might be:

Now we know no other internal principle in a substance for changing its state except desiring, and no other internal activity at all except thinking, together with that which depends on it, the feeling of pleasure or displeasure, and desire or willing.

Here Kant is drawing on a further explanation of life. Kant will describe life as: "the faculty of a being to act in accordance with its representations," where "the faculty of desire [Begehrungsvermögen] is the faculty to be, by means of one's representations, the cause of the objects of these representations" (MM, 6:211; also, KpV, 5:9, Met-M, 29:894; ÜGTP, 8:181; R1034, 15:465). Thus, for embodied beings to be alive is to have a faculty of representation,

\footnotetext{
${ }^{6}$ In many contexts it is important to distinguish two dimensions of the soul: (1) as the ground of representations in the subject, and (2) as the intelligible supersensible ground of activity. In the analogy with life passage, Kant is not sharply distinguishing these, so I will not dwell on this here.

7 (MFNS, 4:544). Compare also, e.g., Met-L2, 28:594; Met-L1, 28:275; DSS, 2:329, as well as many of the concluding passages of the metaphysics lectures on the souls of non-rational animate beings.
} 
specifically desire, through which it can be the cause of the objects of its representations in the material world.

In the remainder of the paragraph, Kant then argues that we should not allow the explanation of life in terms of self-motion to lure us into thinking that matter as matter can be alive. Desiring, thinking, or feeling are internal actions. They are not something that we can represent through the outer senses and we cannot directly see or touch them. According to Kant, however, matter is what is in principle perceivable by such senses, where this will include things like magnetic matter, which is in space, although not perceivable by us (A226/B273, also KU, 5:467). Acts of mind, however, are not in space. So matter as matter-what is in space-cannot be endowed with the powers to act in these ways. It would be tantamount to matter being both in and not in space. Hylozoism is the contradictory position that endows matter with these powers (MFNS, 4:544). And because it is contradictory, he claims "if we seek the cause of any change of matter in life, we will have to seek it forthwith in another substance, different from matter, yet combined with it."

In the analogy with life passage Kant quickly considers hylozoism in relation to organisms, and again rejects living matter as contradictory, presumably for this same reason: life involves inner powers and acts that are not spatial, and so cannot be physical. ${ }^{9}$ Physical matter, as such, cannot be alive. Because it is contradictory, this version of the analogy isn't going to be of use in helping us account for the apparently self-active material causality particular to organisms. After all, the concept of living matter — strictly speaking-doesn't make sense.

\section{$\$ 4-$ The soul as pilot or as builder \& engineer}

After rejecting hylozoism, Kant turns to the material causality particular to organisms and examines whether more of an account can be had by associating with the organism "an alien principle standing in communion with it (a soul)." In this case,

if such a product [(the organism)] is to be a product of nature, organized matter as an instrument of that soul is \{either\} already presupposed, and thus makes that product not the least more comprehensible, or else the soul is made into an artificer of this structure, and the product must be withdrawn from (corporeal) nature. (KU, 5:375-376)

8 (4:544; also e.g., DSS, 2:327 ) Kant makes this argument often, although it is usually compressed.

${ }^{9}$ Another form of hylozoism Kant considers, besides the just discussed living matter (lebenden Materie), is "the possibility of an animated matter [belebten Materie] and of the whole of nature as an animal" (KU, 5:394). Kant, however, does not seem to hold this form of hylozoism to be contradictory (just unexplanatory), and so it is not what he has in mind in the analogy. 
Here Kant considers two options for how the immaterial soul could stand in communion with the organized body.

On the first, the soul uses the body like a tool, as though it were, say, a pilot in a ship. He rejects this as a way of understanding the formative power of organisms because it doesn't actually make this power more comprehensible. It is like trying to comprehend the selfmaintaining powers of a horse by appealing to its rider. What we want to understand is the power in the body (the horse) to organize and produce itself. Proposing that there is an immaterial principle wielding or piloting that body is a non-sequitur. Such a principle presupposes the body (the ship or horse) is already given, with whatever formative powers of self-maintenance it may have. For this reason, although not contradictory, it's not going to help us comprehend these self-active material powers.

The second option Kant considers is that the soul is itself the craftsman of the body. Continuing with the ship analogy, we might think of the soul as though it were either the ship's builder or an engineer, repairing engine damage while the voyage is underway, or both. Kant rejects this option because on it "the product must be withdrawn from (corporeal) nature." But while it is clear why this proposal would withdraw the producer from material, physical nature, why would it also withdraw the product? After all, the product is the organism, and organisms are in the natural world. Well, as we just saw, in an organism the parts are both cause and effect of each other. They are both producer and produced. So the product is itself, in turn, the producer. But if that is the peculiar structure of the formative power in organisms as material beings, then because on our analogy the producer is immaterial, the product would need to be immaterial also. But that would remove the product from material, physical nature, and make the kind of causality in question not so much that of life (a soul's communion with a body), as that of the connection between two immaterial things.

Since the self-organizing power is not analogous to life in either way, the kind of causal powers we encounter in living beings as living beings cannot explain the natural self-organizing power found in organisms. This self-organizing power is an inner power of self-motion. So the self-organizing power cannot be accounted for through the mere mechanism of nature: matter's outer or inner forces. Yet matter, as matter, is also inert. This puts Kant in a paradoxical situation. Certain material beings present us with a kind of self-motion that cannot be explained, either by the powers found in dead matter, or by appealing to immaterial powers, since these can't figure in a science of such matter. 
Nonetheless, outside the context of natural teleology, Kant will sometimes appeal to life to exposit the inner motions of organisms. For example, in presenting why pre-established harmony is a worse view of the interaction between mind and body than physical influx, he claims that "the soul avails itself of the nerves as instruments [Werkzenge] and through these immediately influences the remaining parts of the body; on the other hand the nerves are also the instruments [Werkzenge] through which the body influences the soul" (Met-M, 29:908, 1782/83). Here the body and the soul work on one another, each being the product and the producer of the other.

This is strikingly similar to the way he has described the causality of the formative power, insofar as the parts of the organism are instruments (Werkzenge) of one another and the whole (KU, 5:374), and the nerves are instruments (Werkzenge) of the body and soul (Met$M, 29: 908)$. This then suggests that the nerves are analogous to the parts of the body that are being used as instruments. The parts of the body that are using the nerves would be analogous to the parts of the body that are using its other parts. And the soul that is acting on the body through the nerves is analogous to the whole organism, with its formative power, that is ordering the parts of the body in relation to one another through these parts.

In this way, the third option for understanding the analogy with life can help make the formative power more comprehensible, even if it is not strictly analogous, and is not admissible in natural teleology. But so long as the context allows abstraction from the soul's immateriality and the body's materiality (as in psychology), it is permissible to appeal to the way that the soul grounds motions in the body. Specifically, souls provide a cohesive account of their psychological, supersensible, and physical powers and thereby account for their paradoxical self-motion, even if this account is not a natural one.

\section{$\$ 5-$ The formative power as a life power?}

Kant introduces the analogy with life to clarify "nature and its capacity in organized products," which he has just characterized through the formative power:

\footnotetext{
An organized being is thus not a mere machine, for that has only a motive power, while the organized being possesses in itself a formative power, and indeed one that it communicates to the matter, which does not have it (it organizes the latter): thus it has a self-propagating formative power, which cannot be explained through the capacity for movement alone (that is, mechanism). (KU, 5:374)
}

Ina Goy has argued that it is ambiguous whether Kant holds the formative power is material or immaterial $(2014,53)$. The analogy with life shows that it is not. 
First, we have seen why the formative power can seem immaterial. Organisms are not dead matter, only changed by external (or chemical) causes, but have a self-propagating formative power, which seems to be a limited kind of self-motion. "We know no other internal principle in a substance for changing its state except desiring" (MFNS, 4:544). And, in general, " [a]n internally active power in a being is called life, our own state is a state of representation $<$ status repraesentativus $>$, accordingly in a living being we can always imagine a power of representation <vim repraesentativam $>$ " (Met-V, 28:448-449). A subject with powers of representation, however, is immaterial, and has a supersensible soul. Since the formative power is expressed in the self-movement of organisms, it is like such an immaterial soul. Thus, it too can seem immaterial.

This seeming, however, must be deceptive. Even prior to introducing the formative power Kant has clarified that as natural ends, organized beings are bodies: physical, material beings $(K U, 5: 373)$. He has argued that insofar as the formative power is cognitively admissible in any physical natural science, such as natural teleology, it will be a physical non-living power, like attraction and repulsion or combustion and acidification. Perhaps Kant holds every organism, necessarily, is a living being with a soul, but such supersensible souls cannot be objects of study in sciences of the sensible, natural world..$^{10}$

Furthermore, we saw that Kant rejects the analogy between the formative power of organisms and life on the grounds that, if the analogy were exact, then the material body itself would be immaterial. This was because life was the faculty of an immaterial being to interact with a material one. The very same reason would apply to the formative power. So the formative power cannot be immaterial.

In this respect, Kant rejects the Lebenskräfte of the vitalists. After all, they are lifepowers. They are attempts to explain the formative power of the organism through an analogy with life. Even if there is something sound in the motivation behind positing such powers, the analogy cannot strictly hold.

Should we then conclude that Kant's formative power is a material power? If we could determinately cognize this power, it would be material. Still, if claiming it is material carries the connotation that it belongs to the mechanism of nature, then Kant's answer is equally

\footnotetext{
${ }^{10}$ In "Kant on Plants" I argue that in fact Kant holds every organism, necessarily, is alive. So if I am right, we must regulatively judge both (a) that there is a formative power belonging to the material organism, and (b) that there is a soul that is an immaterial life principle standing in communion with this organism. (a) belongs to natural teleology, (b) does not, although (b) would belong to, say, rational psychology.
} 
"no." After all, we must investigate organisms as natural ends (KU, 5:373). We can make sense of their structure only through the ideas we posit of them and their species-forms. Their formative powers are self-propagating powers which act both to maintain the order among their parts, and to take new matter into their organism. We make sense of these powers through an analogy with our own will: just as our will acts to bring about its ends, so their formative powers act to bring about the organism. Unlike in our case, however, we don't have firsthand knowledge of a subject possessing these ends. So we can only judge reflectively that it is as though the formative power were acting for an end, without being able to claim that there is, in nature, such a real cause. Nonetheless, the only way that Kant thinks natural teleology can make sense of natural ends is through such reflective judgments. In this respect, we must reflectively posit non-mechanical (non-chemical) formative powers-powers quite similar to the Lebenskräfte of the vitalists - even if there will never be a Newton "of a blade of grass" $(K U, 5: 400)$. 


\section{Bibliography}

Berg, Hein van der (2009): "Kant on vital forces. Metaphysical concerns versus scientific practice”. In: Onnasch, Ernst-Otto (Ed.): Kants Philosophie der Natur. Berlin, Boston: De Gruyter, 115-136.

Ginsborg, Hannah (2015): The Normativity of Nature: Essays on Kant's Critique of Judgement. Oxford: Oxford University Press, USA.

Goy, Ina (2014): “Epigenetic theories: Caspar Friedrich Wolff and Immanuel Kant.” In: Goy, Ina/Watkins, Eric (Ed.): Kant's Theory of Biology. Berlin, Boston: De Gruyter, 43-60.

McLaughlin, Peter (2014). "Mechanical explanation in the "critique of the teleological power of judgment.” In: Goy, Ina/Watkins, Eric (Ed.): Kant's Theory of Biology. Berlin, Boston: De Gruyter, 149-166.

Newton, Alexandra (2017): "Kant on animal and human pleasure". In Canadian Journal of Philosophy, 47:4, 518-540.

Nunez, Tyke (forthcoming): "Kant on plants: self-activity, representations, and the analogy with life". In Philosophers' Imprint. 